\title{
Electronically excited molecular nitrogen and molecular oxygen in the high-latitude upper atmosphere
}

\author{
A. S. Kirillov \\ Polar Geophysical Institute of the Kola Science Centre RAS, Apatity, 184209, Russia \\ Received: 14 May 2007 - Revised: 14 March 2008 - Accepted: 6 May 2008 - Published: 28 May 2008
}

\begin{abstract}
Relative vibrational populations of triplet $B^{3} \Pi_{g}$, $W^{3} \Delta_{u}, B^{\prime 3} \Sigma_{u}^{-}$states of $\mathrm{N}_{2}$ and the $b^{1} \Sigma_{g}^{+}$state of $\mathrm{O}_{2}$ are calculated for different altitudes of the high-latitude upper atmosphere during auroral electron precipitation. It is shown that collisional processes cause a wavelength shift in the distribution of relative intensities for 1PG $\Delta v=3$ sequence of $\mathrm{N}_{2}$. The calculation of relative populations for vibrational levels $v=1-5$ of the $b^{1} \Sigma_{g}^{+}$state in the auroral ionosphere has not given an agreement with experimental results. Preliminary estimation of the contribution of the reaction $\mathrm{O}_{2}^{+}+\mathrm{NO}$ to the production of $\mathrm{O}_{2}\left(b^{1} \Sigma_{g}^{+}\right)$on the basis of a quantumchemical approximation does not allow for an explanation of the observable vibrational population of the $b^{1} \Sigma_{g}^{+}$state in the aurora.
\end{abstract}

Keywords. Atmospheric composition and structure (Airglow and aurora) - Ionosphere (Auroral ionosphere)

\section{Introduction}

Electronically excited $\mathrm{N}_{2}$ and $\mathrm{O}_{2}$ molecules are the subject of intensive theoretical and experimental studies related to radiational processes in the auroral upper atmosphere (Cartwright et al., 1972; Vallance Jones, 1974; Cartwright, 1978; Morrill and Benesch, 1996), the airglow in the region of lower thermosphere - mesosphere (Broadfoot and Kendall, 1968; Shefov et al., 2006), sprites in the middle atmosphere above large thunderstorm systems (Morrill et al., 1998; Bucsela et al., 2003), laser plasmas and gas discharges (Delcroix et al., 1976; Kamaratos, 1997, 2005a, b, 2006), etc. One of the motivations for the studies was to investigate the role of collisional molecular processes in the electronic excitation and deexcitation of molecules of main atmospheric gases. The collisional lifetime of an electronically

Correspondence to: A. S. Kirillov

(kirillov@pgia.ru) excited molecule decreases with the increase in atmospheric density and therefore intermolecular and intramolecular electron energy transfers should be dominant in the redistribution of excitation energies between various states of $\mathrm{N}_{2}$ and $\mathrm{O}_{2}$ molecules.

The emissions of first positive group (the transition $B^{3} \Pi_{g} \rightarrow A^{3} \Sigma_{u}^{+}$in molecular nitrogen) and atmospheric bands (the transition $b^{1} \Sigma_{g}^{+} \rightarrow X^{3} \Sigma_{g}^{-}$in molecular oxygen) are especially pronounced in the spectra of the aurora (Vallance Jones, 1974), the nigthglow (Broatfoot and Kendall, 1968; Shefov et al., 2006), sprites (Morrill et al., 1998), and the laboratory afterglow (Hays and Oskam, 1973; Piper, 1994; Kamaratos, 1997, 2005a, b, 2006).

The kinetics of the electronically excited state $B^{3} \Pi_{g}$ is related to the excitation and deexcitation of other triplet states of $\mathrm{N}_{2}$. In several papers (Rotem et al., 1981, 1982; Sadeghi and Setser, 1981; Bachmann et al., 1992, 1993) it was shown for laboratory conditions that there is a collisional coupling between the $B^{3} \Pi_{g}$ state and triplet $A^{3} \Sigma_{u}^{+}, W^{3} \Delta_{u}, B^{3} \Sigma_{u}^{-}$ states. A similar coupling between the $b^{1} \Sigma_{g}^{+}$state and Herzberg states of $\mathrm{O}_{2}$ was studied in (Bednarek et al., 1994, 1997; Shiau et al., 1998; Kalogerakis et al., 2000; Pejakovic et al., 2003). Moreover, Kamaratos (1997, 2005a, b, 2006) has established the enhancement of $\mathrm{N}_{2}\left(B^{3} \Pi_{g}, v\right)$ production in flowing nitrogen afterglows in the case of the addition of discharged $\mathrm{O}_{2}$. He suggested the energy transfer reaction of the metastable singlet oxygen $\mathrm{O}_{2}\left(a^{1} \Delta_{g}\right)$ with metastable triplet nitrogen $\mathrm{N}_{2}\left(A^{3} \Sigma_{u}^{+}\right)$as a possible mechanism of the enhancement. Piper (1988) and Schurath (1975) have studied the formation of $\mathrm{N}_{2}\left(B^{3} \Pi_{g}, v\right)$ and $\mathrm{O}_{2}\left(b^{1} \Sigma_{g}^{+}, v\right)$ molecules in energy pooling reactions between $\mathrm{N}_{2}\left(A^{3} \Sigma_{u}^{+}, v\right)$ and between $\mathrm{O}_{2}\left(a^{1} \Delta_{g}, v\right)$ molecules, respectively.

The main aim of this work is the study of the influence of collisional processes on vibrational populations of triplet states of $\mathrm{N}_{2}$ and the $b^{1} \Sigma_{g}^{+}$state of $\mathrm{O}_{2}$ at altitudes of the high-latitude upper atmosphere. Our study is based on the results of calculations of rate coefficients for the electronic

Published by Copernicus Publications on behalf of the European Geosciences Union. 
quenching in collisions with the participation of $\mathrm{N}_{2}$ and $\mathrm{O}_{2}$ molecules made by Kirillov (2004a, 2008a, b $\mathrm{b}^{1}$ ). A principal advantage of those papers was a suggested method allowing for the calculation of branching ratios for products of the interaction of electronically excited molecules. Therefore, this study is devoted to the model of electronic kinetics of $\mathrm{N}_{2}$ and $\mathrm{O}_{2}$, taking into account detailed consideration of product branching ratios for collisions of electonically excited nitrogen and oxygen molecules.

\section{Model}

The model of the electronic kinetics of $\mathrm{N}_{2}$ and $\mathrm{O}_{2}$ in the auroral upper atmosphere in this work is similar to that of Cartwright et al. (1972), Cartwright (1978), Morrill and Benesch (1996). A main difference in this work consists of a more detailed consideration of product channels in collisions of excited molecules. Since here the main attention is paid to the $B^{3} \Pi_{g}$ state from electronically excited states of molecular nitrogen, we have therefore not included in our consideration the lowest vibrational levels $(v \leq 6)$ of the $A^{3} \Sigma_{u}^{+}$state. Also in the study of electronic kinetics of $\mathrm{O}_{2}$ for high-latitude lower thermosphere and mesosphere by Kirillov $(2008 \mathrm{~b})^{1}$, it was found that the influence of Herzberg $c^{1} \Sigma_{u}^{-}, A^{\prime 3} \Delta_{u}$, $A^{3} \Sigma_{u}^{+}$states on the vibrational population of the $b^{1} \Sigma_{g}^{+}$state is negligible. Therefore, we neglect the influence of the Herzberg states on the production of $\mathrm{O}_{2}\left(b^{1} \Sigma_{g}^{+}\right)$in the auroral ionosphere and don't take into account the production of these three states in this model.

Here we do not consider the energy transfer reactions $\mathrm{O}_{2}\left(a^{1} \Delta_{g}\right)+\mathrm{O}_{2}\left(a^{1} \Delta_{g}\right)$ and $\mathrm{O}_{2}\left(a^{1} \Delta_{g}\right)+\mathrm{N}_{2}\left(A^{3} \Sigma_{u}^{+}\right)$. Firstly, we have no branching ratios for the reactions needed to take into account the interactions in our detailed model of electronic kinetics of $\mathrm{N}_{2}$ and $\mathrm{O}_{2}$. Secondly, Gattinger and Vallance Jones (1973) have presented ratios of the rates of the production of $\mathrm{O}_{2}\left(a^{1} \Delta_{g}\right)$ and $\mathrm{N}_{2}\left(A^{3} \Sigma_{u}^{+}\right)$to the values of intensities of the $427.8 \mathrm{~nm}$ emission in the IBC III aurora. The ratios show that the concentration of metastable oxygen can be increased to the value of $10^{7}-10^{8} \mathrm{~cm}^{-3}$ only after a few tens of minutes of auroral precipitation. One of the aims of this work is the consideration of collisions of electronically excited $\mathrm{N}_{2}$ and $\mathrm{O}_{2}$ with the ground state molecules. So we have limited this study to the first minutes of auroral precipitation, where we can apply steady-state balance equations for the calculation of concentrations of electronically excited molecules. The estimation of the contribution of singlet oxygen in electronic kinetics of $\mathrm{N}_{2}$ and $\mathrm{O}_{2}$ in the auroral ionosphere during an intensive aurora is the subject of our future studies.

\footnotetext{
${ }^{1}$ Kirillov, A. S.: Electronic kinetics of main atmospheric components in high-latitude lower thermosphere and mesosphere, Ann. Geophys., to be submitted, 2008b.
}

Therefore here we have included the following processes of the excitation and quenching of electronically excited $\mathrm{N}_{2}$ and $\mathrm{O}_{2}$ molecules.

1. The electronic excitation by auroral electron impact

$$
\begin{aligned}
& \mathrm{N}_{2}\left(X^{1}, v=0\right)+e_{a} \rightarrow \mathrm{N}_{2}(\gamma, v)+e_{a}, \\
& \gamma=A^{3}(v \geq 7), W^{3}, B^{3}, B^{\prime 3}, C^{3}, \\
& \mathrm{O}_{2}\left(X^{3}, v=0\right)+e_{a} \rightarrow \mathrm{O}_{2}\left(b^{1}, v\right)+e_{a} .
\end{aligned}
$$

The effective method of "excitation energy costs" was suggested by Gordiets and Konovalov (1991); Sergienko and Ivanov (1993); Kozelov et al. (1995), where rates of the processes (1), (2) can be calculated using the value of the energy dissipated by auroral electrons in $1 \mathrm{~cm}^{3}$. Here we apply the data presented by Kozelov et al. (1995).

2. The spontaneous radiative transitions with the emission of bands of the first positive group (1PG), the WuBenesch system (WB), the afterglow system (AG), the second positive group (2PG), the Vegard-Kaplan system (VK) for $\mathrm{N}_{2}$ and atmospheric system (A) for $\mathrm{O}_{2}$ :

$$
\begin{aligned}
& \mathrm{N}_{2}\left(B^{3}, v\right) \leftrightarrow \mathrm{N}_{2}\left(A^{3}, v^{\prime}\right)+h v_{1 \mathrm{PG}}, \\
& \mathrm{N}_{2}\left(B^{3}, v\right) \leftrightarrow \mathrm{N}_{2}\left(W^{3}, v^{\prime}\right)+h v_{\mathrm{WB}}, \\
& \mathrm{N}_{2}\left(B^{3}, v\right) \leftrightarrow \mathrm{N}_{2}\left(B^{\prime}, v^{\prime}\right)+h v_{\mathrm{AG}}, \\
& \mathrm{N}_{2}\left(C^{3}, v\right) \rightarrow \mathrm{N}_{2}\left(B^{3}, v^{\prime}\right)+h v_{2 \mathrm{PG}}, \\
& \mathrm{N}_{2}\left(A^{3}, v\right) \rightarrow \mathrm{N}_{2}\left(X^{1}, v^{\prime}\right)+h v_{\mathrm{VK}}, \\
& \mathrm{O}_{2}\left(b^{1}, v\right) \rightarrow \mathrm{O}_{2}\left(X^{3}, v^{\prime}\right)+h v_{\mathrm{A}} .
\end{aligned}
$$

Einstein coefficients for radiational spontaneous transitions are taken according to Gilmore et al. (1992) for processes (3a-e) and according to Vallance Jones (1974) for the process (4).

3. Intermolecular electron energy transfers in molecular collisions

$$
\begin{aligned}
\mathrm{N}_{2}(Y, v) & +\mathrm{N}_{2}\left(X^{1}, v=0\right) \rightarrow \mathrm{N}_{2}\left(X^{1}, v^{\prime \prime} \geq 0\right) \\
& +\mathrm{N}_{2}\left(A^{3}, W^{3}, B^{\prime 3}, v^{\prime}\right), \\
Y & =A^{3}(v \geq 7), W^{3}, B^{\prime 3} \\
\mathrm{~N}_{2}\left(B^{3}, v\right) & +\mathrm{N}_{2}\left(X^{1}, v=0\right) \rightarrow \mathrm{N}_{2}\left(X^{1}, v^{\prime \prime} \geq 0\right) \\
& +\mathrm{N}_{2}\left(B^{3}, v^{\prime}\right)
\end{aligned}
$$


with an exchange of electron configurations,

$$
\begin{aligned}
\mathrm{N}_{2}(Y, v) & +\mathrm{N}_{2}\left(X^{1}, v=0\right) \rightarrow \mathrm{N}_{2}\left(X^{1}, v^{\prime \prime} \geq 0\right) \\
& +\mathrm{N}_{2}\left(B^{3}, v^{\prime}\right), \\
Y & =A^{3}(v \geq 7), W^{3}, B^{\prime 3} \\
\mathrm{~N}_{2}\left(B^{3}, v\right) & +\mathrm{N}_{2}\left(X^{1}, v=0\right) \rightarrow \mathrm{N}_{2}\left(X^{1}, v^{\prime \prime} \geq 0\right) \\
& +\mathrm{N}_{2}\left(A^{3}, W^{3}, B^{\prime 3}, v^{\prime}\right)
\end{aligned}
$$

with the exchange and the $\sigma_{g} \rightarrow \pi_{u}$ and $\pi_{u} \rightarrow \sigma_{g}$ changes in electronic configurations, respectively, and

$$
\begin{aligned}
\mathrm{O}_{2}\left(b^{1}, v\right) & +\mathrm{O}_{2}\left(X^{3}, v=0\right) \rightarrow \mathrm{O}_{2}\left(X^{3}, v^{\prime \prime} \geq 0\right) \\
& +\mathrm{O}_{2}\left(a^{1}, b^{1}, v^{\prime}\right)
\end{aligned}
$$

with the exchange. Here we use the results of the calculations for rate coefficients made by Kirillov (2004a, $\left.2008 \mathrm{a}, \mathrm{b}^{1}\right)$. Electron energy transfers in collisions of $\mathrm{N}_{2}\left(A^{3} \Sigma_{u}^{+}, v \geq 7\right)$ with $\mathrm{O}_{2}$ with both the production of $\mathrm{O}_{2}\left(c^{1} \Sigma_{u}^{-}, A^{\prime} \Delta_{u}, A^{3} \Sigma_{u}^{+}\right)$and the dissociation of $\mathrm{O}_{2}$ molecule are considered according to Kirillov (2008a, $\left.b^{1}\right)$.

4. Intramolecular electron energy transfers in molecular collisions

$\mathrm{N}_{2}(Y, v)+\mathrm{N}_{2}\left(X^{1}, v=0\right) \rightarrow \mathrm{N}_{2}\left(B^{3}, v^{\prime}\right)+\mathrm{N}_{2}\left(X^{1}, v=0\right)$, $Y=A^{3}(v \geq 7), W^{3}, B^{\prime 3}$,

$\mathrm{N}_{2}\left(B^{3}, v\right)+\mathrm{N}_{2}\left(X^{1}, v=0\right) \rightarrow \mathrm{N}_{2}\left(Y, v^{\prime}\right)+\mathrm{N}_{2}\left(X^{1}, v=0\right)$, $Y=A^{3}, W^{3}, B^{\prime 3}$.

In a case of similar collisions of an electronically excited nitrogen molecule with oxygen molecule or atom we propose similar magnitudes of rate coefficients.

Intramolecular processes for the $b^{1} \Sigma_{g}^{+}$state in a collision with an $\mathrm{O}_{2}$ molecule are negligible according to Kirillov (2008a). Rate coefficients for the quenching by $\mathrm{N}_{2}$ and $\mathrm{O}$ were measured by Bloemink et al. (1998), Kalogerakis et al. (2002, 2004). The results of their measurements are sometimes uncertain and limited to separate vibrational levels of the state. Moreover, now we do not have any estimation of branching ratios for the products of the collision processes; therefore, we have not taken into consideration the quenching by $\mathrm{N}_{2}$ and $\mathrm{O}$ in our model calculations and believe that the processes do not principally change relative vibrational populations in $\mathrm{O}_{2}\left(b^{1} \Sigma_{g}^{+}\right)$.

5. An interaction of metastable $\mathrm{O}\left({ }^{1} \mathrm{D}\right)$ atom with $\mathrm{O}_{2}$ molecule will be described in Sect. 4 .

\section{Electronically excited $\mathbf{N}_{2}$}

The $C^{3} \Pi_{u}$ state of $\mathrm{N}_{2}$ is only in the model which has the radiational lifetime sufficiently less than the collisional one for altitudes of the upper atmosphere. Since rate coefficients for the electronic quenching for vibrational levels $v=0-4$ of the state are about $(1-10) \times 10^{-11} \mathrm{~cm}^{3} \mathrm{~s}^{-1}$ by $\mathrm{N}_{2}$ molecules and (3-5) $\times 10^{-10} \mathrm{~cm}^{3} \mathrm{~s}^{-1}$ by $\mathrm{O}_{2}$ molecules (Pancheshnyi et al., 2000; Dilecce et al., 2006), so the collisional lifetime at the altitude of $80 \mathrm{~km}$ is about $10^{-4} \mathrm{~s}$ in comparison with the value $4 \times 10^{-8} \mathrm{~s}$ for the radiational lifetime (Gilmore et al., 1992). Therefore, in our model we do not consider collisional molecular processes for the $C^{3} \Pi_{u}$ state. This means that the shape of the vibrational population for the state is universal for all considered altitudes of the upper atmosphere. Rates of the excitation and quenching for vibrational levels of the state are calculated by taking into account processes (1) and (3d), respectively. Other considered triplet $A^{3} \Sigma_{u}^{+}(v \geq 7), B^{3} \Pi_{g}, W^{3} \Delta_{u}, B^{\prime} \Sigma_{u}^{-}$states have longer radiational lifetimes and the influence of collisional processes on vibrational distributions of the states at altitudes of the lower thermosphere has to be important.

To calculate the population $N_{v}^{Y}$ of the $v$-th vibrational level of the $Y$-th electronic state we need a system of steadystate equations for all considered vibrational levels of $A^{3} \Sigma_{u}^{+}$, $B^{3} \Pi_{g}, W^{3} \Delta_{u}, B^{\prime} \Sigma_{u}^{-}, C^{3} \Pi_{u}$ states. So we used in our calculations the following steady-state equations for the five electronic states of $\mathrm{N}_{2}$ :

$$
\begin{aligned}
& Q^{A} \cdot q_{v}^{A}+\sum_{v^{\prime}} A_{v^{\prime} v}^{B A} \cdot N_{v^{\prime}}^{B}+\sum_{Y=A, W, B, B^{\prime} ; v^{\prime}} k_{v^{\prime} v}^{* Y A}\left[\mathrm{~N}_{2}\right] \cdot N_{v^{\prime}}^{Y}+ \\
& +\sum_{v^{\prime}} k_{v^{\prime} v}^{\dagger B A}\left(\left[\mathrm{~N}_{2}\right]+\left[\mathrm{O}_{2}\right]+[\mathrm{O}]\right) \cdot N_{v^{\prime}}^{B}=\left\{\sum_{v^{\prime}} A_{v v^{\prime}}^{A B}\right. \\
& +\sum_{v^{\prime}} A_{v v^{\prime}}^{A X}+\sum_{Y=A, W, B, B^{\prime} ; v^{\prime}} k_{v v^{\prime}}^{* A Y}\left[\mathrm{~N}_{2}\right]+ \\
& +\sum_{v^{\prime}} k_{v v^{\prime}}^{\dagger A B}\left(\left[\mathrm{~N}_{2}\right]+\left[\mathrm{O}_{2}\right]+[\mathrm{O}]\right) \\
& \left.+k_{v}^{* A O 2}\left[\mathrm{O}_{2}\right]\right\} \cdot N_{v}^{A}, \\
& Q^{B} \cdot q_{v}^{B}+\sum_{Y=A, W, B^{\prime}, C ; v^{\prime}} A_{v^{\prime} v}^{Y B} \cdot N_{v^{\prime}}^{Y} \\
& +\sum_{Y=A, W, B, B^{\prime} ; v^{\prime}} k_{v^{\prime} v}^{* Y B}\left[\mathrm{~N}_{2}\right] \cdot N_{v^{\prime}}^{Y}+ \\
& +\sum_{Y=A, W, B^{\prime} ; v^{\prime}} k_{v^{\prime} v}^{\dagger Y B}\left(\left[\mathrm{~N}_{2}\right]+\left[\mathrm{O}_{2}\right]+[\mathrm{O}]\right) \cdot N_{v^{\prime}}^{Y} \\
& =\left\{\sum_{Y=A, W, B^{\prime} ; v^{\prime}} A_{v v^{\prime}}^{B Y}+\right. \\
& +\sum_{Y=A, W, B, B^{\prime} ; v^{\prime}} k_{v v^{\prime}}^{* B Y}\left[\mathrm{~N}_{2}\right] \\
& \left.+\sum_{Y=A, W, B^{\prime} ; v^{\prime}} k_{v v^{\prime}}^{\dagger B Y}\left(\left[\mathrm{~N}_{2}\right]+\left[\mathrm{O}_{2}\right]+[\mathrm{O}]\right)\right\} \cdot N_{v}^{B},(8 \mathrm{~b})
\end{aligned}
$$

$Q^{W} \cdot q_{v}^{W}+\sum_{v^{\prime}} A_{v^{\prime} v}^{B W} \cdot N_{v^{\prime}}^{B}$ 
Table 1. Applied rate coefficients in Eq. (8a).

\begin{tabular}{ccccccc}
\hline$v$ & $k_{v}^{* A A}$ & $k_{v}^{* A B}$ & $k_{v}^{* A W}$ & $k_{v}^{* A B^{\prime}}$ & $k_{v}^{* A O 2}$ & $k_{v}^{\dagger} A B$ \\
\hline 7 & $2.2(-13)^{(*)}$ & $8.2(-13)$ & $8.3(-15)$ & - & $3.6(-12)$ & $1.2(-13)$ \\
8 & $1.7(-13)$ & $9.9(-14)$ & $2.4(-15)$ & - & $3.6(-12)$ & $6.7(-15)$ \\
9 & $2.2(-13)$ & $1.6(-12)$ & $2.0(-15)$ & - & $3.2(-12)$ & $1.9(-13)$ \\
10 & $4.0(-13)$ & $8.6(-12)$ & $2.6(-14)$ & - & $3.2(-12)$ & $2.7(-12)$ \\
11 & $1.1(-12)$ & $1.5(-12)$ & $3.4(-13)$ & - & $3.0(-12)$ & $1.0(-13)$ \\
12 & $1.4(-12)$ & $3.1(-12)$ & $9.2(-13)$ & - & $2.9(-12)$ & $4.3(-13)$ \\
13 & $1.3(-12)$ & $4.5(-12)$ & $3.6(-13)$ & $4.4(-15)$ & $2.8(-12)$ & $5.2(-12)$ \\
14 & $6.2(-13)$ & $1.3(-12)$ & $7.7(-14)$ & $4.8(-14)$ & $2.6(-12)$ & $3.2(-13)$ \\
15 & $3.6(-13)$ & $4.1(-12)$ & $1.5(-13)$ & $2.1(-14)$ & $2.5(-12)$ & $1.0(-12)$ \\
16 & $2.7(-13)$ & $1.5(-12)$ & $1.6(-12)$ & $1.6(-14)$ & $2.3(-12)$ & $9.9(-12)$ \\
17 & $8.2(-13)$ & $3.6(-12)$ & $1.6(-12)$ & $2.4(-13)$ & $2.2(-12)$ & $2.9(-13)$ \\
18 & $3.3(-13)$ & $8.2(-13)$ & $3.5(-13)$ & $3.4(-13)$ & $2.1(-12)$ & $3.7(-12)$ \\
19 & $1.1(-12)$ & $2.8(-12)$ & $3.1(-13)$ & $1.2(-13)$ & $2.0(-12)$ & $2.6(-12)$ \\
20 & $5.3(-13)$ & $9.4(-13)$ & $1.4(-12)$ & $1.5(-13)$ & $1.8(-12)$ & $1.6(-12)$ \\
21 & $7.6(-13)$ & $1.8(-12)$ & $1.9(-13)$ & $9.3(-14)$ & $1.7(-12)$ & $1.3(-11)$ \\
22 & $5.6(-13)$ & $1.5(-12)$ & $4.7(-13)$ & $1.9(-13)$ & $1.8(-12)$ & $1.2(-12)$ \\
23 & $3.4(-13)$ & $8.0(-13)$ & $7.1(-13)$ & $1.1(-13)$ & $1.3(-12)$ & $1.3(-11)$ \\
\hline
\end{tabular}

${ }^{(*)} 2.2(-13)$ means $2.2 \times 10^{-13} \mathrm{~cm}^{3} \mathrm{~s}^{-1}$.

Table 2. Applied rate coefficients in Eq. (8b).

\begin{tabular}{cccccccc}
\hline$v$ & $k_{v}^{* B A}$ & $k_{v}^{* B B}$ & $k_{v}^{* B W}$ & $k_{v}^{* B B^{\prime}}$ & $k_{v}^{\dagger B A}$ & $k_{v}^{\dagger B W}$ & $k_{v}^{\dagger B B^{\prime}}$ \\
\hline 0 & $5.6(-12)$ & - & $6.9(-14)$ & - & $4.1(-13)$ & $3.6(-10)$ & - \\
1 & $2.1(-12)$ & $7.7(-15)$ & $4.0(-13)$ & - & $9.7(-14)$ & $9.9(-12)$ & - \\
2 & $1.5(-11)$ & $7.2(-15)$ & $3.3(-13)$ & - & $2.9(-12)$ & $1.9(-12)$ & - \\
3 & $2.6(-12)$ & $4.1(-13)$ & $1.7(-13)$ & - & $1.0(-12)$ & $1.8(-12)$ & $7.0(-17)$ \\
4 & $6.6(-12)$ & $1.5(-12)$ & $8.7(-13)$ & $1.2(-13)$ & $3.7(-12)$ & $7.6(-13)$ & $6.2(-13)$ \\
5 & $7.2(-12)$ & $1.0(-12)$ & $4.6(-12)$ & $2.2(-13)$ & $2.5(-12)$ & $5.3(-12)$ & $1.3(-12)$ \\
6 & $3.8(-12)$ & $1.5(-13)$ & $6.5(-12)$ & $2.1(-13)$ & $1.0(-11)$ & $4.6(-11)$ & $1.7(-12)$ \\
7 & $7.4(-12)$ & $3.8(-12)$ & $4.1(-12)$ & $2.1(-13)$ & $2.1(-12)$ & $5.4(-11)$ & $1.8(-12)$ \\
8 & $2.9(-12)$ & $5.7(-12)$ & $1.0(-12)$ & $4.0(-13)$ & $1.0(-11)$ & $1.1(-11)$ & $1.8(-12)$ \\
9 & $5.0(-12)$ & $4.4(-12)$ & $2.9(-12)$ & $8.9(-13)$ & $2.3(-11)$ & $2.4(-12)$ & $1.9(-12)$ \\
10 & $4.6(-12)$ & $3.2(-12)$ & $7.3(-12)$ & $1.5(-12)$ & $2.2(-11)$ & $3.1(-12)$ & $2.5(-12)$ \\
\hline
\end{tabular}

$$
\begin{aligned}
& +\sum_{Y=A, W, B, B^{\prime} ; v^{\prime}} k_{v^{\prime} v}^{* Y W}\left[\mathrm{~N}_{2}\right] \cdot N_{v^{\prime}}^{Y}+ \\
& +\sum_{v^{\prime}} k_{v^{\prime} v}^{\dagger B W}\left(\left[\mathrm{~N}_{2}\right]+\left[\mathrm{O}_{2}\right]+[\mathrm{O}]\right) \cdot N_{v^{\prime}}^{B} \\
& =\left\{\sum_{v^{\prime}} A_{v v^{\prime}}^{W B}+\sum_{Y=A, W, B, B^{\prime} ; v^{\prime}} k_{v v^{\prime}}^{* W Y}\left[\mathrm{~N}_{2}\right]+\right. \\
& \left.+\sum_{v^{\prime}} k_{v v^{\prime}}^{\dagger W B}\left(\left[\mathrm{~N}_{2}\right]+\left[\mathrm{O}_{2}\right]+[\mathrm{O}]\right)\right\} \cdot N_{v}^{W},
\end{aligned}
$$

$$
\begin{aligned}
& Q^{B^{\prime}} \cdot q_{v}^{B^{\prime}}+\sum_{v^{\prime}} A_{v^{\prime} v}^{B B^{\prime}} \cdot N_{v^{\prime}}^{B}+\sum_{Y=A, W, B, B^{\prime} ; v^{\prime}} \\
& k_{v^{\prime} v}^{* Y B^{\prime}}\left[\mathrm{N}_{2}\right] \cdot N_{v^{\prime}}^{Y}+
\end{aligned}
$$

$$
\begin{aligned}
& +\sum_{v^{\prime}} k_{v^{\prime} v}^{\dagger B B^{\prime}}\left(\left[\mathrm{N}_{2}\right]+\left[\mathrm{O}_{2}\right]+[\mathrm{O}]\right) \cdot N_{v^{\prime}}^{B} \\
= & \left\{\sum_{v^{\prime}} A_{v v^{\prime}}^{B^{\prime} B}+\sum_{Y=A, W, B, B^{\prime} ; v^{\prime}} k_{v v^{\prime}}^{* B^{\prime} Y}\left[\mathrm{~N}_{2}\right]+\right. \\
& \left.+\sum_{v^{\prime}} k_{v v^{\prime}}^{\dagger B^{\prime} B}\left(\left[\mathrm{~N}_{2}\right]+\left[\mathrm{O}_{2}\right]+[\mathrm{O}]\right)\right\} \cdot N_{v}^{B^{\prime}},
\end{aligned}
$$$$
Q^{C} \cdot q_{v}^{C}=\sum_{v^{\prime}} A_{v v^{\prime}}^{C B} \cdot N_{v}^{C},
$$

where $Q^{Y}$ is the production rate of the $Y$-th state by auroral electrons (in $\mathrm{cm}^{-3} \mathrm{~s}^{-1}$ ), $q_{v}^{Y}$ is the Franck-Condon factor for the transition $X^{1} \Sigma_{g}^{+}, v=0 \rightarrow Y, v, A_{v v^{\prime}}^{Y Z}$ is the spontaneous transition probability for the transition $Y, v \rightarrow Z, v^{\prime}$, $k_{v v^{\prime}}^{* Y Z}$ and $k_{v v^{\prime}}^{\dagger Y Z}$ are rate coefficients for intermolecular and 
Table 3. Applied rate coefficients in Eq. (8c).

\begin{tabular}{cccccc}
\hline$v$ & $k_{v}^{* W A}$ & $k_{v}^{* W B}$ & $k_{v}^{* W W}$ & $k_{v}^{* W B^{\prime}}$ & $k_{v}^{\dagger W B}$ \\
\hline 0 & $4.8(-13)$ & $9.8(-14)$ & - & - & $5.1(-10)$ \\
1 & $3.9(-12)$ & $2.0(-13)$ & - & - & $6.4(-12)$ \\
2 & $2.3(-12)$ & $1.1(-12)$ & $1.7(-15)$ & - & $3.4(-12)$ \\
3 & $3.9(-12)$ & $9.1(-12)$ & $2.2(-14)$ & - & $3.0(-12)$ \\
4 & $1.3(-11)$ & $2.2(-11)$ & $6.5(-14)$ & $3.0(-17)$ & $5.2(-13)$ \\
5 & $1.8(-12)$ & $9.2(-12)$ & $1.4(-13)$ & $1.1(-15)$ & $2.7(-12)$ \\
6 & $1.2(-12)$ & $1.4(-11)$ & $3.3(-13)$ & $1.9(-14)$ & $2.9(-11)$ \\
7 & $4.5(-12)$ & $1.3(-11)$ & $7.8(-13)$ & $1.2(-13)$ & $8.6(-11)$ \\
8 & $2.2(-12)$ & $9.7(-12)$ & $1.3(-13)$ & $6.5(-13)$ & $3.4(-11)$ \\
9 & $3.5(-12)$ & $8.5(-12)$ & $1.5(-13)$ & $2.3(-12)$ & $3.1(-12)$ \\
10 & $4.3(-12)$ & $4.5(-12)$ & $7.1(-13)$ & $6.8(-12)$ & $3.1(-12)$ \\
11 & $2.5(-12)$ & $5.7(-12)$ & $1.5(-12)$ & $2.0(-12)$ & $1.1(-11)$ \\
12 & $1.0(-12)$ & $2.3(-12)$ & $1.6(-12)$ & $1.7(-12)$ & $2.8(-11)$ \\
13 & $1.2(-12)$ & $5.2(-12)$ & $2.6(-12)$ & $2.7(-12)$ & $5.5(-11)$ \\
14 & $6.0(-13)$ & $6.0(-12)$ & $3.9(-12)$ & $5.6(-13)$ & $6.4(-11)$ \\
15 & $4.7(-13)$ & $4.8(-12)$ & $2.7(-12)$ & $6.6(-13)$ & $7.4(-12)$ \\
16 & $5.1(-13)$ & $3.2(-12)$ & $3.6(-12)$ & $3.8(-13)$ & $3.9(-12)$ \\
17 & $3.2(-13)$ & $4.7(-12)$ & $1.3(-12)$ & $4.8(-13)$ & $8.7(-12)$ \\
18 & $2.6(-13)$ & $1.5(-12)$ & $3.0(-12)$ & $2.0(-12)$ & $1.7(-11)$ \\
\hline
\end{tabular}

Table 4. Applied rate coefficients in Eq. (8d).

\begin{tabular}{cccccc}
\hline$v$ & $k_{v}^{* B^{\prime} A}$ & $k_{v}^{* B^{\prime} B}$ & $k_{v}^{* B^{\prime} W}$ & $k_{v}^{* B^{\prime} B^{\prime}}$ & $k_{v}^{\dagger B^{\prime} B}$ \\
\hline 0 & $4.1(-12)$ & $3.2(-12)$ & $3.2(-14)$ & - & $2.4(-13)$ \\
1 & $9.1(-12)$ & $1.2(-11)$ & $3.4(-13)$ & - & $5.2(-13)$ \\
2 & $3.0(-12)$ & $4.7(-12)$ & $2.0(-12)$ & $8.4(-16)$ & $1.1(-12)$ \\
3 & $1.0(-12)$ & $6.8(-12)$ & $4.5(-12)$ & $1.2(-14)$ & $2.3(-12)$ \\
4 & $1.4(-12)$ & $5.0(-12)$ & $3.1(-12)$ & $3.0(-14)$ & $4.7(-12)$ \\
5 & $3.0(-12)$ & $7.2(-12)$ & $4.4(-12)$ & $5.8(-14)$ & $8.7(-12)$ \\
6 & $2.2(-12)$ & $6.6(-12)$ & $1.9(-12)$ & $1.2(-13)$ & $1.5(-11)$ \\
7 & $1.1(-12)$ & $5.5(-12)$ & $8.2(-13)$ & $2.7(-13)$ & $2.3(-11)$ \\
8 & $3.4(-13)$ & $3.0(-12)$ & $1.3(-12)$ & $9.4(-14)$ & $3.4(-11)$ \\
9 & $1.2(-12)$ & $3.4(-12)$ & $1.7(-12)$ & $6.0(-14)$ & $4.7(-11)$ \\
10 & $1.6(-12)$ & $2.8(-12)$ & $1.3(-12)$ & $2.5(-13)$ & $6.1(-11)$ \\
11 & $4.5(-13)$ & $3.0(-12)$ & $1.0(-12)$ & $4.7(-13)$ & $7.6(-11)$ \\
12 & $1.4(-13)$ & $1.6(-12)$ & $1.6(-12)$ & $5.9(-13)$ & $9.0(-11)$ \\
13 & $2.0(-13)$ & $1.9(-12)$ & $6.6(-13)$ & $8.8(-13)$ & $1.0(-10)$ \\
\hline
\end{tabular}

intramolecular electron energy transfer processes with the quenching of $Y, v$ and the excitation of $Z, v^{\prime}$, respectively. Here we suggest to consider the rate of an intramolecular process independent of the kind of the collision with $\mathrm{N}_{2}$, $\mathrm{O}_{2}$ or $\mathrm{O}$. So the sum of the concentrations $\left[\mathrm{N}_{2}\right]+\left[\mathrm{O}_{2}\right]+[\mathrm{O}]$ is included in steady-state Eqs. (8a-d) for the contributions of intramolecular processes. Contributions of intermolecular electron energy transfer processes in collisions of $\mathrm{N}_{2}\left(A^{3} \Sigma_{u}^{+}\right.$, $v \geq 7)$ with $\mathrm{O}_{2}$, with both the production of $\mathrm{O}_{2}\left(c^{1} \Sigma_{u}^{-}, A^{\prime 3} \Delta_{u}\right.$, $\left.A^{3} \Sigma_{u}^{+}\right)$and the dissociation of $\mathrm{O}_{2}$ molecule, are included in Eq. (8a) and rate coefficients are denoted by $k_{v}^{* A O 2}$. Applied rate coefficients $k_{v}^{* A A}, k_{v}^{* A B}, k_{v}^{* A W}, k_{v}^{* A B^{\prime}}, k_{v}^{* A O 2}$ and $k_{v}^{\dagger} A B$

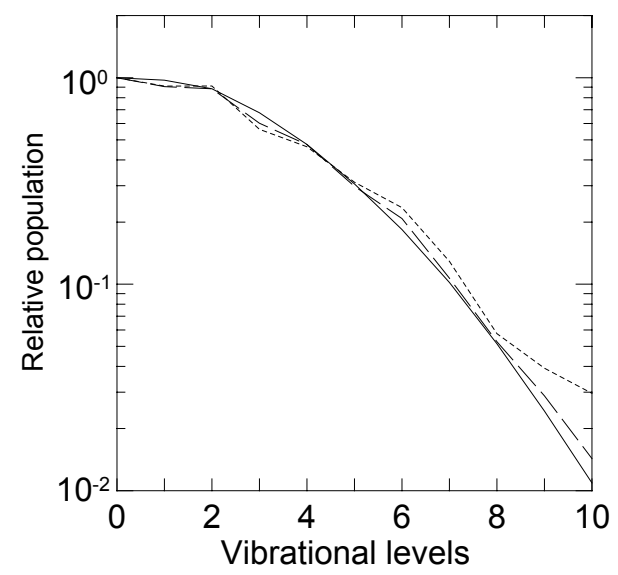

Fig. 1. Calculated relative vibrational populations $\left[\mathrm{N}_{2}\left(\mathrm{~B}^{3} \Pi_{g}, v\right)\right] /\left[\mathrm{N}_{2}\left(B^{3} \Pi_{g}, v=0\right)\right]$ at altitudes 80,95 and $150 \mathrm{~km}$ (dotted, dashed and solid lines, respectively).

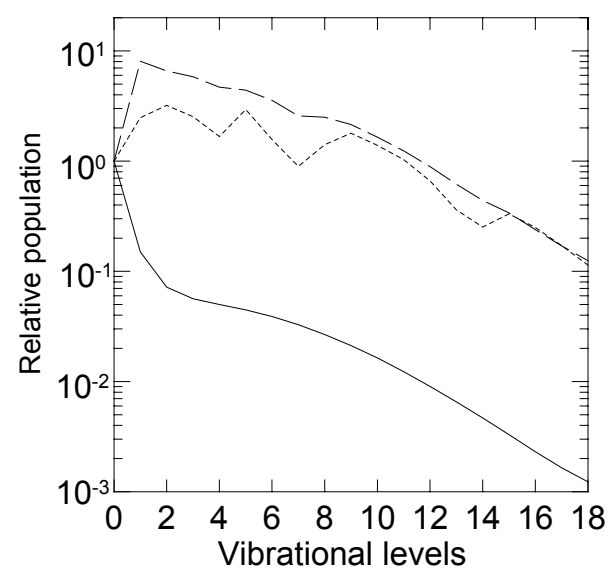

Fig. 2. The same as in Fig. 1 but for the $W^{3} \Delta_{u}$ state of $\mathrm{N}_{2}$.

for intermolecular and intramolecular processes in Eq. (8a) are shown in Table 1. The rate coefficients $k_{v}^{* Y Z}$ and $k_{v}^{\dagger} Y Z$ mean sums of $k_{v v^{\prime}}^{* Y Z}$ and $k_{v v^{\prime}}^{\dagger Y Z}$ on quantum number $v^{\prime}$. Similar rate coefficients for $B^{3} \Pi_{g}, W^{3} \Delta_{u}, B^{\prime} \Sigma_{u}^{-}$states of $\mathrm{N}_{2}$ applied in Eqs. (8b-d) are shown in Tables $2-4$, respectively.

Results of our calculation of relative vibrational populations $\left(\left[\mathrm{N}_{2}\left(B^{3} \Pi_{g}, v\right)\right] /\left[\mathrm{N}_{2}\left(B^{3} \Pi_{g}, v=0\right)\right],\left[\mathrm{N}_{2}\left(W^{3} \Delta_{u}, v\right)\right] /\right.$ $\left.\left[\mathrm{N}_{2}\left(W^{3} \Delta_{u}, v=0\right)\right],\left[\mathrm{N}_{2}\left(B^{\prime}{ }^{3} \Sigma_{u}^{-}, v\right)\right] /\left[\mathrm{N}_{2}\left(B^{\prime} \Sigma_{u}^{-}, v=0\right)\right]\right)$ at altitudes of 80, 95 and $150 \mathrm{~km}$ of auroral upper atmosphere are shown in Figs. 1-3, respectively. It is seen from Figs. 2 and 3 that there is the influence of collisional processes on the distributions of $W^{3} \Delta_{u}$ and $B^{\prime 3} \Sigma_{u}^{-}$states. For the $W^{3} \Delta_{u}$ state the increase in the density of the atmosphere causes the rise of the population for the vibrational levels $v \geq 1$. For the $B^{\prime}{ }^{3} \Sigma_{u}^{-}$state the similar increase causes the rise in the population of the lowest $v=0-2$ vibrational levels in comparison with the maximum in the distributions. 
Table 5. Relative intensities of bands for $1 \mathrm{PG} \Delta v=3$ sequence.

\begin{tabular}{lcccccccc}
\hline & \multicolumn{7}{c}{$v^{\prime}\left(B^{3} \Pi_{g}\right) \rightarrow v^{\prime \prime}$} & $\left(A^{3} \Sigma_{u}^{+}\right), \lambda(\mathrm{nm})$ \\
Experimental data or results of the calculation & $3 \rightarrow 0$ & $4 \rightarrow 1$ & $5 \rightarrow 2$ & $6 \rightarrow 3$ & $7 \rightarrow 4$ & $8 \rightarrow 5$ & $9 \rightarrow 6$ & $10 \rightarrow 7$ \\
& 687.5 & 678.9 & 670.5 & 662.4 & 654.5 & 646.9 & 639.5 & 632.3 \\
\hline Vallance Jones (1974) & 0.46 & 0.96 & 1 & 0.73 & 0.48 & 0.25 & 0.12 & 0.045 \\
$130-200 \mathrm{~km}$ & 0.43 & 0.87 & 1 & 0.83 & 0.54 & 0.28 & 0.12 & 0.045 \\
$110 \mathrm{~km}$ & 0.42 & 0.91 & 1 & 0.87 & 0.55 & 0.28 & 0.13 & 0.05 \\
$95 \mathrm{~km}$ & 0.39 & 0.89 & 1 & 0.97 & 0.58 & 0.30 & 0.15 & 0.06 \\
$80 \mathrm{~km}$ & 0.34 & 0.79 & 0.95 & 1 & 0.63 & 0.29 & 0.18 & 0.12 \\
$45 \mathrm{~km}$ (the pressure $\sim 1$ Torr) & 0.50 & 0.86 & 0.71 & 1 & 0.46 & 0.24 & 0.22 & 0.18 \\
\hline
\end{tabular}

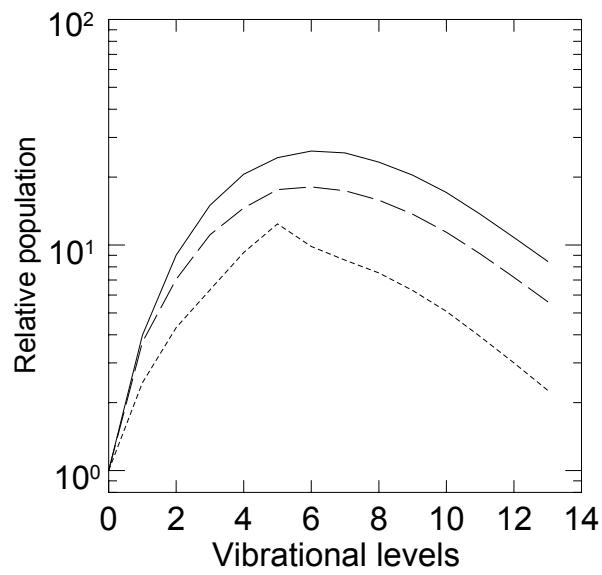

Fig. 3. The same as in Fig. 1 but for the $B^{\prime 3} \Sigma_{u}^{-}$state of $\mathrm{N}_{2}$.

The $B^{3} \Pi_{g}$ state does not show sufficient variations in the relative population (see Fig. 1). We see an evident increase in the population only for $v=9,10$ in the region of high densities. However, a dependence of $1 \mathrm{PG}$ emission intensities on atmospheric density is important in problems related to the production of red lower border of auroral arcs (Benesch, 1981, 1983; Morrill and Benesch, 1996), a movement of the electronic excitation to the lowest vibrational levels of the $B^{3} \Pi_{g}$ state in laboratory afterglow (Pravilov et al., 1988; Piper, 1994), a change in relative population of the $B^{3} \Pi_{g}$ state at different altitudes in sprites (Morrill et al., 1998; Bucsela et al., 2003).

Benesch $(1981,1983)$ has suggested that the change in the colour of the lower border in the type B aurora from red to deep crimson could be related to an increased collision frequency in lower thermosphere. He has considered a wavelength shift of the relative intensities of the 1PG $\Delta v=3$ sequence from normal auroral observations to results of laboratory measurements made at the pressure of $\sim 1$ Torr. A comparison of calculated relative intensities of the bands for the 1PG $\Delta v=3$ sequence with data of Vallance Jones (1974) is presented in Table 5. The comparison shows a dependence of the band intensities on the density of the atmosphere. So there is a movement of the band of maximal intensity from the infrared to the red region with the increase in the density of the atmosphere. This fact is in good agreement with the conclusions of Benesch $(1981,1983)$.

\section{Electronically excited $\mathrm{O}_{2}$}

Vallance Jones and Gattinger (1974) and Gattinger and Vallance Jones (1976) in their observations of the auroral ionosphere at Fort Churchill have measured intensities of atmospheric bands of $\mathrm{O}_{2}$ originated during spontaneous radiational transitions from vibrational levels $v=0-5$ of the $b^{1} \Sigma_{g}^{+}$ state. They emphasised an enhancement as a function of the height in the relative strength of the 1-1 band in comparison with bands both from $v=0$ and from $v>1$. The former behaviour was observed by Omholt (1957). The observation of intensities for normal and high auroras by Gattinger and Vallance Jones (1976) has confirmed that the 1-1 atmospheric band shows a strong enhancement with the height of the aurora but, however, for bands with $2 \leq v \leq 5$ there is very little change with the height relative to bands of the 1PG system of $\mathrm{N}_{2}$. Moreover, authors of those papers discussed possible mechanisms of high rates of the excitation of $\mathrm{O}_{2}\left(b^{1} \Sigma_{g}^{+}\right.$, $v=3-5$ ) in auroral ionosphere.

Henriksen and Sivjee (1990) during spectrophotometric observations at Spitsbergen have estimated the vibrational population of the $b^{1} \Sigma_{g}^{+}$state of molecular oxygen in the auroral ionosphere. For their estimation they have used measured intensities of five oxygen atmospheric bands $\left(v=v^{\prime}=1-\right.$ $5)$. In a similar way the measurements have shown an anomalous high population of vibrational levels $v=3-5$ and confirmed the dependence of the relative intensity of the (1-1) bands on the height.

Relative vibrational populations $\left[\mathrm{O}_{2}\left(b^{1} \Sigma_{g}^{+}, \quad v=1-\right.\right.$ $5)] /\left[\mathrm{O}_{2}\left(b^{1} \Sigma_{g}^{+}, \quad v=1\right)\right]$ obtained by Vallance Jones and Gattinger (1974), Gattinger and Vallance Jones (1976), Henriksen and Sivjee (1990) for normal and high auroras are shown in Fig. 4. Also, we have presented here results of the theoretical calculation according to our model for the 
Table 6. Applied rate coefficients in Eq. (9).

\begin{tabular}{ccc}
\hline$v$ & $k_{v}^{* b a}$ & $k_{v}^{* b b}$ \\
\hline 1 & - & $1.4(-11)$ \\
2 & $3.0(-15)$ & $1.5(-12)$ \\
3 & $1.5(-14)$ & $1.5(-13)$ \\
4 & $7.1(-14)$ & $3.2(-14)$ \\
5 & $3.2(-13)$ & $1.3(-13)$ \\
6 & $1.2(-12)$ & $8.2(-13)$ \\
7 & $1.7(-12)$ & $5.1(-12)$ \\
8 & $5.2(-13)$ & $3.2(-11)$ \\
9 & $1.4(-13)$ & $3.6(-12)$ \\
10 & $5.4(-14)$ & $1.5(-13)$ \\
\hline
\end{tabular}

altitude $80 \mathrm{~km}$. To calculate the population $N_{v}^{b}$ of the $v$-th vibrational level of the $\mathrm{b}^{1} \Sigma_{g}^{+}$state of molecular oxygen we used the following steady-state equation:

$$
\begin{aligned}
& Q^{b} \cdot q_{v}^{b}+\sum_{v^{\prime}} k_{v^{\prime} v}^{* b b}\left[\mathrm{O}_{2}\right] \cdot N_{v^{\prime}}^{b} \\
& =\left\{\sum_{v^{\prime}} A_{v v^{\prime}}^{b X}+\sum_{Y=a, b ; v^{\prime}} k_{v v^{\prime}}^{* b Y}\left[\mathrm{O}_{2}\right]\right\} \cdot N_{v}^{b},
\end{aligned}
$$

where $Q^{b}$ is the production rate of the $b^{1} \Sigma_{g}^{+}$state by auroral electrons, $q_{v}^{b}$ is the Franck-Condon factor for the transition $X^{3} \Sigma_{g}^{-}, v=0 \rightarrow b^{1} \Sigma_{g}^{+}, v, A_{v v^{\prime}}^{b X}$ is the spontaneous transition probability for the transition $b^{1} \Sigma_{g}^{+}, v \rightarrow X^{3} \Sigma_{g}^{-}, v^{\prime}, k_{v v^{\prime}}^{* b Y}$ is a rate coefficient for the intermolecular electron energy transfer process with the quenching of $b^{1} \Sigma_{g}^{+}, v$ and the excitation of $Y, v^{\prime}$, respectively. We emphasise that it is here assumed that the quenching of $\mathrm{O}_{2}\left(b^{1} \Sigma_{g}^{+}, v\right)$ in collisions with $\mathrm{N}_{2}$ molecules does not principally change the relative distribution of singlet oxygen shown in Fig. 4. Applied rate coefficients $k_{v}^{* b a}, k_{v}^{* b b}$ for intermolecular processes in Eq. (9) are shown in Table 6.

For the altitude $150 \mathrm{~km}$ we made a similar calculation but the contribution of the process

$$
\mathrm{O}\left({ }^{1} \mathrm{D}\right)+\mathrm{O}_{2}\left(X^{3}, v=0\right) \rightarrow \mathrm{O}\left({ }^{3} \mathrm{P}\right)+\mathrm{O}_{2}\left(b^{1}, v^{\prime}=0,1\right)
$$

is taken into account. According to Green et al. (2000) we believe the yield of the process (10) in inelastic quenching of metastable atomic oxygen by an oxygen molecule is equal to 0.95 . Branching ratios for the production of $v^{\prime}=0$ and 1 are measured by Kalogerakis et al. (2005). They have obtained $k_{v=1} / k_{v=0}=3-4$ in contrast to earlier estimations of Gauthier and Snelling (1974), Lee and Slanger (1978) having values in the interval $0.3-1$. Therefore we adopt $k_{v=1} / k_{v=0}=3.5$ in our calculation.

Metastable atomic oxygen is produced in auroral ionosphere mainly in processes of auroral electron impact with $\mathrm{O}\left({ }^{3} \mathrm{P}\right)$ atoms and a dissociative recombination of $\mathrm{O}_{2}^{+}$ions. We make the calculation with the energy $10^{5} \mathrm{eV}$ dissipated by auroral electrons in $1 \mathrm{~cm}^{3}$ in one second. The rate of the

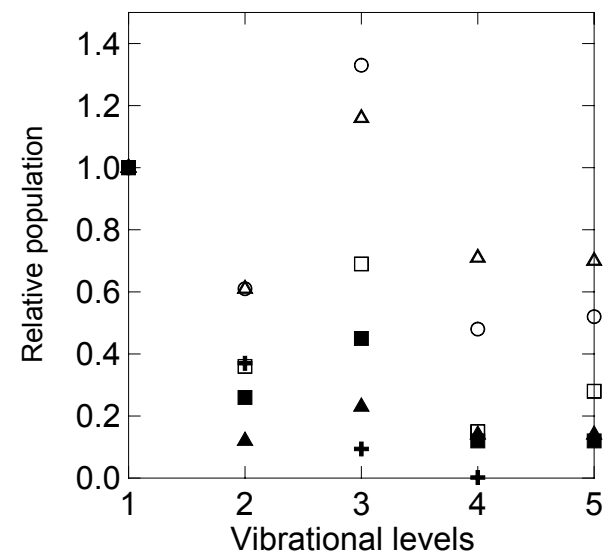

Fig. 4. Relative vibrational populations $\left[\mathrm{O}_{2}\left(b^{1} \Sigma_{g}^{+}, \quad v=1-\right.\right.$ $5)] /\left[\mathrm{O}_{2}\left(b^{1} \Sigma_{g}^{+}, v=1\right)\right]$ : results of our calculation for $h=80 \mathrm{~km}-$ crosses; experimental data of Vallance Jones and Gattinger (1974) - circles, Gattinger and Vallance Jones (1976) for normal and high aurora - open and solid triangles, respectively, Henriksen and Sivjee (1990) for normal and high aurora - open and solid squares, respectively.

$\mathrm{O}\left({ }^{1} \mathrm{D}\right)$ production by electron impact is estimated according to the method of "excitation energy costs" (Kozelov et al., 1995). For the estimation of the contribution of $\mathrm{O}_{2}^{+}$dissociative recombination it is necessary to know the concentrations of the ion and ionospheric electrons at the considered altitude. Swider and Narcisi (1977) have analysed eight auroral ion composition measurements and according to their data the concentration of $\mathrm{O}_{2}^{+}$at the altitude $150 \mathrm{~km}$ is about $0.1-$ 0.3 from the total ion concentration. So we believe in our calculation $\left[\mathrm{O}_{2}^{+}\right]=0.2 \cdot n_{e}$, where $n_{e}$ means the ionospheric electron concentration. The value $n_{e} \sim 1.2 \times 10^{5} \mathrm{~cm}^{-3}$ is obtained from the suggestion of $36 \mathrm{eV}$ for the production of one ionelectron pair in auroral electron interaction with main atmospheric components. Petrignani et al. (2005a, b) have measured quantum exits of $\mathrm{O}\left({ }^{3} \mathrm{P}\right), \mathrm{O}\left({ }^{1} \mathrm{D}\right), \mathrm{O}\left({ }^{1} \mathrm{~S}\right)$ atoms for vibrational levels $v=0-2$ of the $\mathrm{O}_{2}^{+}\left(X^{2} \Pi_{g}\right)$ ion in the dissociative recombination. We use here the value 0.94 for the $O\left({ }^{1} \mathrm{D}\right)$ production in the case of $v=0$ according to their measurements. Therefore we found that the total rate of the $\mathrm{O}\left({ }^{1} \mathrm{D}\right)$ production by auroral electron impact and the dissociative recombination is equal to $\sim 2 \times 10^{3} \mathrm{~s}^{-1}$.

Taking into account rate coefficients of the inelastic interaction of $\mathrm{O}\left({ }^{1} \mathrm{D}\right)$ atoms with $\mathrm{N}_{2}$ and $\mathrm{O}_{2}$ molecules (Sander et al., 2003; Takahashi et al., 2005) and $\mathrm{O}\left({ }^{3} \mathrm{P}\right)$ atom (Closser et al., 2005) we have finally obtained the production rates for $\mathrm{O}_{2}\left(b^{1} \Sigma_{g}^{+}\right)$and $\mathrm{O}_{2}\left(b^{1} \Sigma_{g}^{+}, v=1\right)$ as $1.6 \times 10^{2}$ and $1.25 \times 10^{2} \mathrm{~s}^{-1}$, respectively, at the altitude $150 \mathrm{~km}$. The last value is about 60 times more than the excitation rate of $\mathrm{O}_{2}\left(b^{1} \Sigma_{g}^{+}, v=1\right)$ by the auroral electron impact on $\mathrm{O}_{2}$ (process 2). So we do not show the calculated vibrational population of the $b^{1} \Sigma_{g}^{+}$state at the altitude $150 \mathrm{~km}$ since 


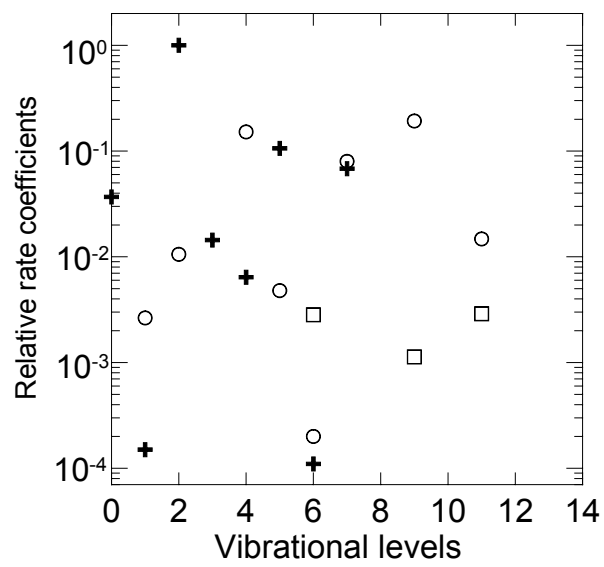

Fig. 5. Calculated relative rate coefficients for the process (11) for vibrational level $v=0$ of the $\mathrm{O}_{2}^{+}\left(X^{2} \Pi_{g}\right)$ ion with $\mathrm{O}_{2}\left(X^{3} \Sigma_{g}, v\right)$, $\mathrm{O}_{2}\left(a^{1} \Delta_{g}, v\right), \mathrm{O}_{2}\left(b^{1} \Sigma_{g}^{+}, v\right)$ productions - squares, circles and crosses, respectively.

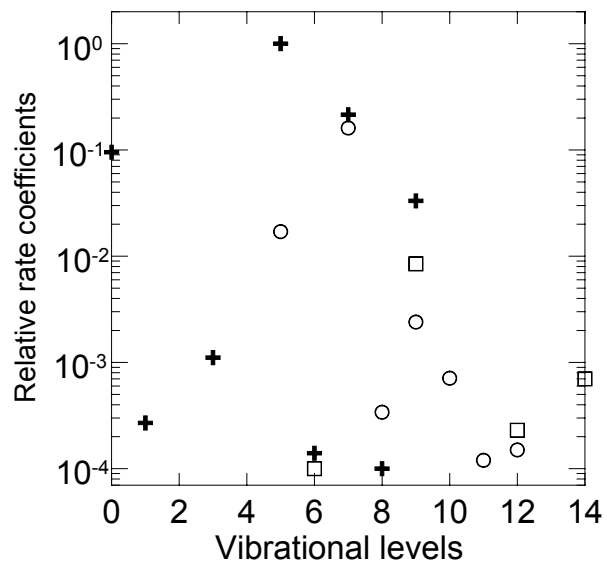

Fig. 6. The same as in Fig. 5 but for vibrational level $v=1$ of the $\mathrm{O}_{2}^{+}\left(X^{2} \Pi_{g}\right)$ ion.

concentrations of $\mathrm{O}_{2}\left(b^{1} \Sigma_{g}^{+}, v>1\right)$ are negligible in comparison with the one of $v=1$.

Henriksen and Sivjee (1990) have mentioned, originally suggested by Slanger (1986), chemical ion-molecular reaction

$\mathrm{O}_{2}{ }^{+}\left(X^{2}, v\right)+\mathrm{NO}\left(X^{2}, v=0\right) \rightarrow \mathrm{O}_{2}{ }^{*}+\mathrm{NO}^{+}\left(X^{1}, v^{\prime}\right)$,

as a possible explanation of the high population of vibrational levels $v=3-5$ of $\mathrm{O}_{2}\left(b^{1} \Sigma_{g}^{+}\right)$in aurora. It is to note that Gattinger and Vallance Jones (1976) have also considered this reaction as a possible mechanism of the effective production of $\mathrm{O}_{2}\left(b^{1} \Sigma_{g}^{+}\right)$in the auroral ionosphere. To verify this suggestion we try in this work to calculate the quantum efficiencies of all possible channels of the process (11). We use formulas of Kirillov (2004b) received on the basis of the Rosen-Zener approximation. Calculations are made

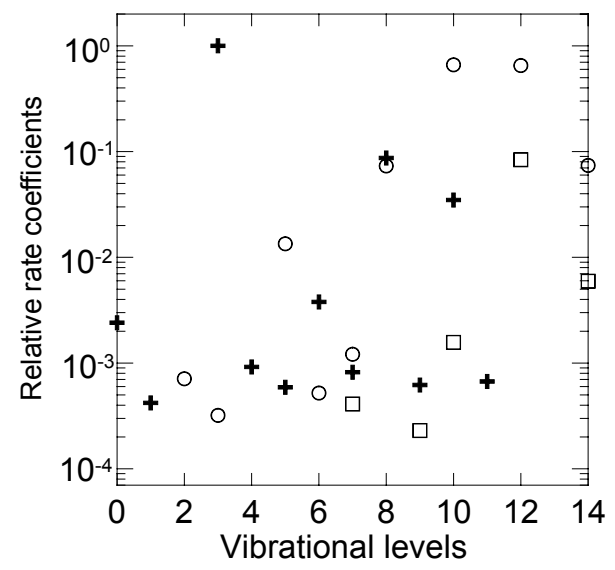

Fig. 7. The same as in Fig. 5 but for vibrational level $v=2$ of the $\mathrm{O}_{2}^{+}\left(X^{2} \Pi_{g}\right)$ ion.

for vibrational levels $v=0-5$ of the ground state $X^{2} \Pi_{g}$ of the molecular oxygen ion. As possible channels of the reaction we consider the production of the molecule $\mathrm{O}_{2}$ in $X^{3} \Sigma_{g}^{-}$, $a^{1} \Delta_{g}, b^{1} \Sigma_{g}^{+}$states. For nitric oxide ion we take into account the production of the only $X^{1} \Sigma^{+}$state since the energy of the first excited $a^{3} \Sigma^{+}$state is more than the allowed exothermic one, according to the reaction.

Calculated relative rate coefficients for the vibrational levels $v=0-2$ of the ground $X^{2} \Pi_{g}$ state of $\mathrm{O}_{2}^{+}$with three exit channels are shown in Figs. 5-7. The normalising is made on partial rate coefficients of vibrational levels $v=2, v=5$ and $v=3$ of the $b^{1} \Sigma_{g}^{+}$state of $\mathrm{O}_{2}$, respectively. It is seen from Fig. 5 that the calculation of the rate coefficients for the process (11) (originally suggested by Slanger, 1986) with the lowest vibrational level $v=0$ of the ground state ion of molecular oxygen points out the dominance of $v=2$ in the production of $\mathrm{O}_{2}\left(b^{1} \Sigma_{g}^{+}\right)$. The exits for levels $v=3-5$ are $1-2$ orders of magnitude lower than the one for $v=2$. The results of the calculation for $v=0$ of $\mathrm{O}_{2}^{+}\left(X^{2} \Pi_{g}\right)$ do not allow one to obtain a higher vibrational population for $v=3$ of the state than for $v=2$ observed by Henriksen and Sivjee (1990), since the quenching rate coefficient for $v=3$ is on one order of magnitude lower than the one for $v=2$ (Kalogerakis et al., 2002; Kirillov, 2008a).

Calculations for $v=1$ and 2 of the ground $X^{2} \Pi_{g}$ state of $\mathrm{O}_{2}^{+}$, shown in Figs. 6 and 7 , point out an effective production of $v=5$ and 3 of $\mathrm{O}_{2}\left(b^{1} \Sigma_{g}^{+}\right)$. Similar estimations for $v=3-5$ have given maximal rate coefficients for $v=9-11$ of $\mathrm{O}_{2}\left(b^{1} \Sigma_{g}^{+}\right)$. So for the correct calculation of the production of $\mathrm{O}_{2}\left(b^{1} \Sigma_{g}^{+}, v\right)$ in the auroral ionosphere we need a full model of vibrational kinetics of molecular oxygen ion. Nevertheless, our preliminary calculation of the rate coefficients for the production of electronically excited $\mathrm{O}_{2}$ in the process (11) have not shown any pronounced high magnitudes for levels $v=3-5$. Therefore we believe that it is necessary 
to consider other mechanisms of the $\mathrm{O}_{2}\left(b^{1} \Sigma_{g}^{+}\right)$production in auroral ionosphere to explain this high vibrational population of $v=3-5$. Maybe the high vibrational population of the $v=3-5$ levels is related to the energy transfer in the collision of metastable atomic nitrogen $\mathrm{N}\left({ }^{2} \mathrm{D}\right)$ with molecular oxygen $\mathrm{O}_{2}$ (Gattinger and Vallance Jones, 1976).

\section{Conclusions}

Here we have presented the results of the calculation for vibrational populations of triplet states of molecular nitrogen and the $b^{1} \Sigma_{g}^{+}$state of molecular oxygen in the highlatitude upper atmosphere. Main distinction of our results from similar model calculations of Cartwright et al. (1972); Cartwright (1978); Morrill and Benesch (1996) is the inclusion of intermolecular and intramolecular electron energy transfers related to collisions of electronically excited $\mathrm{N}_{2}$ and $\mathrm{O}_{2}$ molecules. Moreover, quantum efficiencies of product channels for the processes are taken according to estimations of Kirillov (2004a, 2008a, b ${ }^{1}$ ) based on an application of the Landau-Zener and Rosen-Zener approximations for the theory of molecular collisions (Kirillov, 2004b).

The main results of these calculations are as follows:

1. It is shown that the vibrational populations of $W^{3} \Delta_{u}$ and $B^{\prime} \Sigma_{u}^{-}$states of molecular nitrogen have a strong dependence on the altitude for auroral ionosphere. The dependence is related to an important role of collisional processes in the redistribution of the electronic excitation between triplet states of $\mathrm{N}_{2}$ during molecular inelastic interaction. The increase in the density of the atmosphere causes the rise of relative population of the lowest vibrational level $v=0$ for the $B^{\prime 3} \Sigma_{u}^{-}$state and on the contrary the depletion for the same level of the $W^{3} \Delta_{u}$ state.

2. Our estimation of relative band intensities for the $1 P G$ $\Delta v=3$ sequence for different altitudes of the atmosphere shows a dependence on the atmospheric density. There is a pronounced wavelength shift of maximal intensity in the region of lower wavelengths. This result is in good agreement with conclusions of Benesch (1981, 1983) that collisional processes could be responsible for the change in the colour in the lower border of the type B aurora.

3. The theoretical calculation of the vibrational population of the $b^{1} \Sigma_{g}^{+}$state of molecular oxygen in the auroral ionosphere has shown some disagreement with experimental data of Vallance Jones and Gattinger (1974), Gattinger and Vallance Jones (1976), Henriksen and Sivjee (1990). Using theoretical formulas based on the Rosen-Zener approximation according to Kirillov (2004b) we have calculated the quantum efficiencies of product channels for the process (11) suggested by
Slanger (1986), for the explanation of the experimentally observed distribution. It was found in the calculation that the quantum exits of the production of $\mathrm{O}_{2}\left(b^{1} \Sigma_{g}^{+}, v=3-5\right)$ in the reaction of $\mathrm{O}_{2}^{+}\left(X^{2} \Pi_{g}, v=0\right)$ ion with $\mathrm{NO}$ molecule are insufficient to explain the high vibrational populations of the levels $v=3-5$ estimated from measurements of atmospheric band intensities.

Acknowledgements. The main part of this paper was given as an oral presentation at the 33rd Annual European Meeting on Atmospheric studies by Optical Methods in Kiruna, Sweden (28 August1 September 2006). This research is supported by the Division of Physical Sciences of RAS (program "Plasma processes in the solar system"), by the grants 05-05-64271, 06-05-65044 and 08-0500226 of Russian Foundation for Basic Research (RFBR) and by the Nordic Council of Ministers through grant 087043-60105, Network for Groundbased Optical Auroral Research in the Arctic Region.

Topical Editor U.-P. Hoppe thanks two anonymous referees for their help in evaluating this paper.

\section{References}

Bachmann, R., Li, X., Ottinger, Ch., and Vilesov, A. F.: Molecular-beam study of the collisional intramolecular coupling of $\mathrm{N}_{2}\left(\mathrm{~B}^{3} \Pi_{g}\right)$ with the $\mathrm{N}_{2}\left(\mathrm{~A}^{3} \Sigma_{u}^{+}\right)$and $\mathrm{N}_{2}\left(\mathrm{~W}^{3} \Delta_{u}\right)$ states, J. Chem. Phys., 96, 5151-5164, 1992.

Bachmann, R., Li, X., Ottinger, Ch., Vilesov, A. F., and Wulfmeier, V.: Vibrational-state-to-state collision-induced intramolecular energy transfer $\mathrm{N}_{2}\left(\mathrm{~A}^{3} \Sigma_{u}^{+}, \mathrm{v}^{\prime} \rightarrow \mathrm{B}^{3} \Pi_{g}, \mathrm{v}^{\prime}\right)$, J. Chem. Phys., 98, 8606-8625, 1993.

Bednarek, G., Wayne, R. P., Wildt, J., and Fink, E. H.: The yield of $\mathrm{O}_{2}\left(\mathrm{~b}^{1} \Sigma_{g}^{+}, \mathrm{v}=0\right)$ produced by quenching of $\mathrm{O}_{2}\left(\mathrm{~A}^{3} \Sigma_{u}^{+}, \mathrm{v}=8\right)$ by $\mathrm{O}_{2}$, Chem. Phys., 185, 251-261, 1994.

Bednarek, G., Wayne, R. P., Wildt, J., and Fink, E. H.: Erratum, The yield of $\mathrm{O}_{2}\left(\mathrm{~b}^{1} \Sigma_{g}^{+}, \mathrm{v}=0\right)$ produced by quenching of $\mathrm{O}_{2}\left(\mathrm{~A}^{3} \Sigma_{u}^{+}\right.$, $\mathrm{v}=8$ ) by $\mathrm{O}_{2}$, [Chem. Phys., 185, 251-261, 1994], Chem. Phys., 222, 113-114, 1997.

Benesch, W.: Mechanism for the auroral red lower border, J. Geophys. Res., 86, 9065-9072, 1981

Benesch, W.: Intersystem collisional transfer of excitation in low altitude aurora, J. Chem. Phys., 78, 2978-2983, 1983.

Bloemink, H. I., Copeland, R. A., and Slanger, T. G.: Collisional removal of $\mathrm{O}_{2}\left(\mathrm{~b}^{1} \Sigma_{g}^{+}, \mathrm{v}=1,2\right)$ by $\mathrm{O}_{2}, \mathrm{~N}_{2}$, and $\mathrm{CO}_{2}$, J. Chem. Phys., 109, 4237-4245, 1998.

Broadfoot, A. L. and Kendall, K. R.: The airglow spectrum, 300010000 A, J. Geophys. Res., 73, 426-428, 1968.

Bucsela, E., Morrill, J., Heavner, M., Siefring, C., Berg, S., Hampton, D., Moudry, D., Wescott E., and Sentman, D.: $\mathrm{N}_{2}\left(\mathrm{~B}^{3} \Pi_{g}\right)$ and $\mathrm{N}_{2}^{+}\left(\mathrm{A}^{2} \Pi_{u}\right)$ vibrational distributions observed in sprites, J. Atmos. Sol. Terr. Phys., 65, 583-590, 2003.

Cartwright, D. C.: Vibrational populations of the excited states of $\mathrm{N}_{2}$ under auroral conditions, J. Geophys. Res., 83, 517-531, 1978.

Cartwright, D. C., Trajmar, S., and Williams, W.: The excitation of $\mathrm{O}_{2}$ in auroras, Ann. Geophys., 28, 397-401, 1972, http://www.ann-geophys.net/28/397/1972/. 
Closser, K. D., Pejakovic, D. A., and Kalogerakis, K. S.: $\mathrm{O}\left({ }^{1} \mathrm{D}\right)$ relaxation by $\mathrm{O}\left({ }^{3} \mathrm{P}\right)$, EOS, Trans. AGU, 86, F1460, 2005.

Delcroix, J. L., Ferreira, C. M., and Ricard, A.: Metastable atoms and molecules in ionized gases, in Principles of laser plasmas, G. Bakefi, Editor, Wiley, New York, 159-233, 1976.

Dilecce, G., Ambrico, P. F., and De Benedictis, S.: OODR-LIF direct measurement of $\mathrm{N}_{2}\left(\mathrm{C}^{3} \Pi_{u}, \mathrm{v}=0-4\right)$ electronic quenching and vibrational relaxation rate coefficients by $\mathrm{N}_{2}$ collision, Chem. Phys. Lett., 431, 241-246, 2006.

Gattinger, R. L. and Vallance Jones, A.: Observation and interpretation of $\mathrm{O}_{2}$ 1.27- $\mu$ emission enhancement in aurora, J. Geophys. Res., 78, 8305-8313, 1973.

Gattinger, R. L. and Vallance Jones, A.: The vibrational development of the $\mathrm{O}_{2}\left(\mathrm{~b}^{1} \Sigma_{g}^{+}-\mathrm{X}^{3} \Sigma_{g}^{-}\right)$system in auroras, J. Geophys. Res., 81, 4789-4792, 1976.

Gauthier, M. J. E. and Snelling, D. R.: Production de $\mathrm{O}_{2}\left(\mathrm{~b}^{1} \Sigma_{g}^{+}\right)$, v' $=0,1$ et 2 par la reaction $\mathrm{O}\left(2^{1} \mathrm{D}_{2}\right)+\mathrm{O}_{2}\left(\mathrm{X}^{3} \Sigma_{g}^{-}\right)$, Can. J. Chem., 52, 4007-4015, 1974.

Gilmore, F. R., Laher, R. R., and Espy, P. J.: Franck-Condon factors, r-centroids, electronic transition moments, and Einstein coefficients for many nitrogen and oxygen band systems, J. Phys. Chem. Ref. Data, 21, 1005-1107, 1992.

Gordiets, B. F. and Konovalov, V. P.: The excitation and ionization of ionospheric gas by high-energetic electrons, Geomagnetizm i Aeronomiya, 31, 649-656, 1991 (in Russian).

Green, J. G., Shi, J., and Barker, J. R.: Photochemical kinetics of vibrationally excited ozone produced in the $248 \mathrm{~nm}$ photolysis of $\mathrm{O}_{2} / \mathrm{O}_{3}$ mixtures, J. Phys. Chem. A, 104, 6218-6226, 2000.

Hays, G. N. and Oskam, H. J.: Population of $\mathrm{N}_{2}\left(\mathrm{~B}^{3} \Pi_{g}\right)$ by $\mathrm{N}_{2}\left(\mathrm{~A}^{3} \Sigma_{u}^{+}\right)$during the nitrogen afterglow, J. Chem. Phys., 59, 1507-1516, 1973.

Henriksen, K. and Sivjee, G. D.: Auroral vibrational population of the $\mathrm{O}_{2}\left(\mathrm{~b}^{1} \Sigma_{g}^{+}, \mathrm{v}^{\prime}\right)$ levels, Planet. Space Sci., 38, 835-840, 1990.

Kalogerakis, K. S., Totth, A., Cosby, P. C., Slanger, T. G., and Copeland, R. A.: Laboratory studies of the production of highly vibrationally excited $\mathrm{O}_{2}\left(\mathrm{a}^{1} \Delta_{g}\right.$ and $\left.\mathrm{b}^{1} \Sigma_{g}^{+}\right)$from $\mathrm{O}_{2}\left(\mathrm{~A}^{3} \Sigma_{u}^{+}\right)$relaxation, EOS, Trans. AGU, 81, F944, 2000.

Kalogerakis, K. S., Copeland, R. A., and Slanger, T. G.: Collisional removal of $\mathrm{O}_{2}\left(\mathrm{~b}^{1} \Sigma_{g}^{+}, \mathrm{v}=2,3\right)$, J. Chem. Phys., 116, 4877-4865, 2002.

Kalogerakis, K. S., Pejakovic, D. A., Copeland, R. A., and Slanger, T. G.: Collisional removal of $\mathrm{O}_{2}\left(\mathrm{~b}^{1} \Sigma_{g}^{+}, \mathrm{v}=1\right)$ by atomic oxygen, EOS, Trans. AGU, 85, F1425, 2004.

Kalogerakis, K. S., Pejakovic, D. A., Copeland, R. A., and Slanger, T. G.: Relative yield of $\mathrm{O}_{2}\left(\mathrm{~b}^{1} \Sigma_{g}^{+}, \mathrm{v}=0\right.$ and 1) in $\mathrm{O}\left({ }^{1} \mathrm{D}\right)+\mathrm{O}_{2}$ collisions, EOS, Trans. AGU, 86, F1461, 2005.

Kamaratos, E.: Orange flame from active nitrogen and oxygen in the absence of a metal catalyst resulting from collisional intersystem crossing into $\mathrm{N}_{2}\left(\mathrm{~B}^{3} \Pi_{g}\right)$, J. Phys. Chem., 101, 2040-2044, 1997.

Kamaratos, E.: A study of background emissions enhancements in nitrogen afterglows, due to addition of discharged $\mathrm{O}_{2}$, in connection with the reactions $\left\{\mathrm{N}_{2}\left(\mathrm{~A}^{3} \Sigma_{u}^{+}, \mathrm{v}\right)+\mathrm{O}\left({ }^{3} \mathrm{P}\right)\right\},\left\{\mathrm{O}_{2}\left(\mathrm{a}^{1} \Delta_{g}\right)+\right.$ $\left.\mathrm{N}\left({ }^{4} \mathrm{~S}\right)\right\}$ and $\left\{\mathrm{O}_{2}\left(\mathrm{a}^{1} \Delta_{g}\right)+\mathrm{N}_{2}\left(\mathrm{~A}^{3} \Sigma_{u}^{+}\right)\right\}$, Cent. Eur. J. Chem., 3, 387-403, 2005a.

Kamaratos, E.: Enhanced UV emissions in active nitrogen and oxygen, Chem. Phys. Lett., 415, 51-57, 2005b.

Kamaratos, E.: Active nitrogen and oxygen: Enhanced emissions and chemical reactions, Chem. Phys., 323, 271-294, 2006.
Kirillov, A. S.: Calculation of rate coefficients of electron energy transfer processes for molecular nitrogen and molecular oxygen, Adv. Space Res., 33, 998-1004, 2004a.

Kirillov, A. S.: Application of Landau-Zener and Rosen-Zener approximations to calculate rates of electron energy transfer processes, Adv. Space Res., 33, 993-997, 2004b.

Kirillov, A. S.: The study of intermolecular energy transfers in electronic energy quenching for molecular collisions $\mathrm{N}_{2}-\mathrm{N}_{2}, \mathrm{~N}_{2}-\mathrm{O}_{2}$, $\mathrm{O}_{2}-\mathrm{O}_{2}$, Ann. Geophys., this issue, 2008a.

Kozelov, B. V., Ivanov, V. E., and Sergienko, T. I.: Excitation of $\mathrm{N}_{2}$, O and $\mathrm{O}_{2}$ by low-energetic electrons, Preprint PGI-95-0297, Apatity, 1995.

Lee, L. C. and Slanger, T. G.: Observations on $\mathrm{O}\left({ }^{1} \mathrm{D} \rightarrow{ }^{3} \mathrm{P}\right)$ and $\mathrm{O}_{2}\left(\mathrm{~b}^{1} \Sigma_{g}^{+} \rightarrow \mathrm{X}^{3} \Sigma_{g}^{-}\right)$following $\mathrm{O}_{2}$ photodissociation, J. Chem. Phys., 69, 4053-4060, 1978.

Morrill, J. S. and Benesch, W. M.: Auroral $\mathrm{N}_{2}$ emissions and the effect of collisional processes on $\mathrm{N}_{2}$ triplet state vibrational populations, J. Geophys. Res., 101, 261-274, 1996.

Morrill, J. S., Bucsela, E. J., Pasko, V. P., Berg, S. L., Heavner, M. J., Moudry, D. R., Benesch, W. M., Wescott E. M., and Sentman, D. D.: Time resolved $\mathrm{N}_{2}$ triplet state vibrational populations and emissions associated with red sprites, J. Atmos. Sol. Terr. Phys., 60, 811-829, 1998.

Omholt, A.: The red and near-infra-red auroral spectrum, J. Atmos. Terr. Phys., 10, 320-324, 1957.

Pancheshnyi, S. V., Starikovskaia, S. M., and Starikovskii, A. Yu.: Collisional deactivation of $\mathrm{N}_{2}\left(\mathrm{C}^{3} \Pi_{u}, \mathrm{v}=0,1,2,3\right)$ states by $\mathrm{N}_{2}$, $\mathrm{O}_{2}, \mathrm{H}_{2}$ and $\mathrm{H}_{2} \mathrm{O}$ molecules, Chem. Phys., 262, 349-357, 2000.

Pejakovic, D. A., Cosby, P. C., Copeland, R. A., and Slanger, T. G.: Laboratory measurements of the $\mathrm{O}_{2}\left(\mathrm{a}^{1} \Delta_{g}, \mathrm{v}=0\right)$ and $\mathrm{O}_{2}\left(\mathrm{~b}^{1} \Sigma_{g}^{+}, \mathrm{v}=0\right)$ yields following collisional removal of $\mathrm{O}_{2}\left(\mathrm{~A}^{3} \Sigma_{u}^{+}, \mathrm{v}=6-10\right)$, EOS, Trans. AGU, 84, F1149, 2003.

Petrignani, A., van der Zande, W. J., Cosby, P. C., Hellberg, F., Thomas, R. D., and Larsson, M.: Vibrationally resolved rate coefficients and branching fractions in the dissociative recombination of $\mathrm{O}_{2}^{+}$, J. Chem. Phys., 122, 014302, doi:10.1063/1.1825991, 2005a.

Petrignani, A., Hellberg, F., Thomas, R. D., Larsson, M., Cosby, P. C., and van der Zande, W. J.: Vibrational dependence in the dissociative recombination of $\mathrm{O}_{2}^{+}$, J. Phys.: Conf. Ser., 4, 182186, 2005b.

Piper, L. G.: State-to-state $\mathrm{N}_{2}\left(\mathrm{~A}^{3} \Sigma_{u}^{+}\right)$energy pooling reactions. II. The formation and quenching of $\mathrm{N}_{2}\left(\mathrm{~B}^{3} \Pi_{g}, \mathrm{v}^{\prime}=1-12\right)$, J. Chem. Phys., 101, 10 229-10 236, 1994.

Piper, L. G.: Further observations on the nitrogen orange afterglow, J. Chem. Phys., 101, 10229-10 236, 1988.

Pravilov, A. M., Smirnova, L. G., and Vilesov, A. F.: The mechanism of $\mathrm{N}_{2}\left(\mathrm{~B}^{3} \Pi_{g}\right)$ deactivation by $\mathrm{N}_{2}$, Chem. Phys. Lett., 144, 469-472, 1988.

Rotem, A., Nadler, I., and Rosenwaks, S.: Laser-induced fluorescence studies of collisional coupling of $\mathrm{N}_{2}\left(\mathrm{~B}^{3} \Pi_{g}\right)$ with $\mathrm{N}_{2}\left(\mathrm{~W}^{3} \Delta_{u}\right)$ and $\mathrm{N}_{2}\left(\mathrm{~A}^{3} \Sigma_{u}^{+}\right)$, Chem. Phys. Lett., 83, 281-286, 1981.

Rotem, A., Nadler, I., and Rosenwaks, S.: Direct observation of collision induced transitions from $\mathrm{N}_{2}\left(\mathrm{~B}^{3} \Pi_{g}\right)$ to $\mathrm{N}_{2}\left(\mathrm{~B}^{3} \Sigma_{u}^{-}\right)$, J. Chem. Phys., 76, 2109-2111, 1982.

Sadeghi, N. and Setser, D. W.: Collisional coupling of $\mathrm{N}_{2}\left(\mathrm{~B}^{3} \Pi_{g}\right)$ and $\mathrm{N}_{2}\left(\mathrm{~W}^{3} \Delta_{u}\right)$ states studied by laser-induced fluorescence, Chem. Phys. Lett., 77, 304-308, 1981. 
Sander, S. P., Friedl, R. R., Golden, D. M., Kurylo, M. J., Huie, R. E., Orkin, V. L., Moortgat, G. K., Ravishankara, A. R., Kolb, C. E., Molina, M. J., and Finlayson-Pitts, B. J.: Chemical kinetics and photochemical data for use in atmospheric studies, JPL Publication 02-25, JPL, Pasadena, CA, 2003.

Schurath, U.: The energy pooling reaction $2 \mathrm{O}_{2}\left({ }^{1} \Delta_{g}\right) \rightarrow \mathrm{O}_{2}\left({ }^{3} \Sigma_{g}^{-}\right)$ $+\mathrm{O}_{2}\left({ }^{1} \Sigma_{g}^{+}\right)$; formation, relaxation, and quenching of vibrationally excited $\mathrm{O}_{2}\left({ }^{1} \Sigma_{g}^{+}\right)$, J. Photochem., 4, 215-226, 1975.

Sergienko, T. I. and Ivanov, V. E.: A new approach to calculate the excitation of atmospheric gases by auroral electron impact, Ann. Geophys., 11, 717-727, 1993, http://www.ann-geophys.net/11/717/1993/.

Shefov, N. N., Semenov, A. I., and Khomich, V. Yu.: Airglow as indicator of the upper atmospheric structure and dynamics, Geos, Moscow, 2006 (in Russian).
Shiau, T. P., Hwang, E. S., Buijsse, B., and Copeland, R. A.: Vibrational-level-dependent yields of $\mathrm{O}_{2}\left(\mathrm{~b}^{1} \Sigma_{g}^{+}, \mathrm{v}=0\right)$ following collisional removal of $\mathrm{O}_{2}\left(\mathrm{~A}^{3} \Sigma_{u}^{+}, \mathrm{v}\right)$, Chem. Phys. Lett., 282, 369-374, 1998.

Slanger, T. G.: Vibrational excitation in $\mathrm{O}_{2}\left(\mathrm{~b}^{1} \Sigma_{g}^{+}\right)$, Can. J. Phys., 64, 1657-1663, 1986.

Swider, W. and Narcisi, R. S.: Auroral E-region: Ion composition and nitric oxide, Planet. Space Sci., 25, 103-116, 1977.

Takahashi, K., Takeuchi, Y., and Matsumi, Y.: Rate constants of the $\mathrm{O}\left({ }^{1} \mathrm{D}\right)$ reactions with $\mathrm{N}_{2}, \mathrm{O}_{2}, \mathrm{~N}_{2} \mathrm{O}$, and $\mathrm{H}_{2} \mathrm{O}$ at $295 \mathrm{~K}$, Chem. Phys. Lett., 410, 196-200, 2005.

Vallance Jones, A.: Aurora, Geophys. Astrophys. Monogr., D. Reidel, Dordrecht, Netherlands, 1974.

Vallance Jones, A. and Gattinger, R. L.: The $\mathrm{O}_{2}\left(\mathrm{~b}^{1} \Sigma_{g}^{+}-\mathrm{X}^{3} \Sigma_{g}^{-}\right)$ system in aurora, J. Geophys. Res., 79, 4821-4822, 1974. 